Article

\title{
Effect of Glycerol Concentration and Light Intensity on Growth and Biochemical Composition of Arthrospira (Spirulina) Platensis: A Study in Semi-Continuous Mode with Non-Aseptic Conditions
}

\author{
Giorgos Markou 1,*(1), Eleni Kougia ${ }^{1,2}$, Io Kefalogianni ${ }^{2}$, Vasiliki Tsagou ${ }^{2}$, \\ Dimitrios Arapoglou ${ }^{1}$ and Iordanis Chatzipavlidis ${ }^{2}$ \\ 1 Institute of Technology of Agricultural Products, Hellenic Agricultural \\ Organization-Demeter (HAO-Demeter), Leof. Sofokli Venizelou 1, Lykovrysi, 14123 Athens, Greece; \\ eleni-1995@windowslive.com (E.K.); dimarap@yahoo.com (D.A.) \\ 2 Laboratory of General and Agricultural Microbiology, Department of Crop Science, Agricultural University \\ of Athens, GR-118 55 Athens, Greece; bmic7kei@aua.gr (I.K.); tsagouv@hotmail.com (V.T.); \\ chatzipavlidis@aua.gr (I.C.) \\ * Correspondence: gmarkou@itap.com.gr; Tel.: +30-210-28-45-940
}

Received: 9 October 2019; Accepted: 28 October 2019; Published: 4 November 2019

\begin{abstract}
In this study, Arthrospira platensis was grown in the presence of different glycerol concentrations $(0.5-9 \mathrm{~g} / \mathrm{L})$ under three light intensities $(5,10$ and $15 \mathrm{Klux})$ in semi-continuous mode and under non-axenic conditions. The aim of this study was to investigate the growth performance, the biomass biochemical composition and any interactions between A. platensis and bacteria that would potentially grow as well on glycerol. The results here show that glycerol did not have any positive effect on biomass production of A. platensis. In contrast, it was observed that by increasing glycerol concentration the growth performance of $A$. platensis was restricted, while a gradual increase of bacteria population was observed, which apparently outcompeted and repressed A. platensis growth. Chlorophyll fluorescence measurements (Quantum Yields) revealed that glycerol was not an inhibiting factor per se of photosynthesis. On the other hand, cyanobacterial biomass grown on glycerol displayed a higher content in proteins and lipids. Especially, protein productivity was enhanced around 15-35\% with the addition of glycerol compared to the control. In distinction, carbohydrate and photosynthetic pigments (phycocyanin and chlorophyll- $\alpha$ ) content decreased with the increase of glycerol concentration. The results here suggest that $A$. platensis did not utilize glycerol for biomass production but most probably as metabolic energy carrier towards synthesis of proteins and lipids, which are more energy consuming metabolites compared to carbohydrates. The study revealed that the addition of glycerol at amounts of $0.5-1.5 \mathrm{~g} / \mathrm{L}$ could be a strategy to improve protein productivity by A. platensis.
\end{abstract}

Keywords: Arthrospira platensis (Spirulina); mixotrophy; glycerol; protein production

\section{Introduction}

Arthrospira platensis (commonly known as Spirulina) is a photosynthetic cyanobacterium of high nutritional value due to its high content in proteins (up to $70 \%$ ), polyunsaturated fatty acids, vitamins etc. In fact, A. platensis along with Chlorella vulgaris are the most widely commercially produced microalgal/cyanobacterial species worldwide and are sold mainly as food supplements. A. platensis is exclusively produced under phototrophic mode in open ponds either indoors or outdoors. However, autotrophic mode displays a major drawback related to light limitations due 
to the poor penetration of light into the higher depths of the cultures, which subsequently result in low biomass concentrations (typically $300-500 \mathrm{mg} / \mathrm{L}$ of dry mass) [1]. To overcome this limitation, microalgal/cyanobacterial cultivation could be performed under mixotrophic mode, where organic molecules, such as glucose, acetate, glycerol etc. could be utilized as an energy and/or carbon source. Mixotrophy combines autotrophic photosynthesis and heterotrophic assimilation of organic carbon and it has been demonstrated that is advantageous over phototrophic or heterotrophic modes giving higher biomass concentrations and productivities [2].

Among various organic compounds that are good candidates for microalgal mixotrophic cultivation, glycerol is an ideal one because it is industrially produced and available at high amounts and low cost, mainly because of the biodiesel production industry, where glycerol is a by-product of the transesterification of fatty acids to methyl esters (biodiesel). It is estimated that biodiesel market will have an annual growth of around $4.5 \%$, reaching around $40 \mathrm{Mm}^{3}$ in 2022 [3]. From each $\mathrm{m}^{3}$ of biodiesel, approximately $0.1 \mathrm{~m}^{3}$ of crude glycerol is generated. Moreover, glycerol is widely used as a sweetener in the food industry in pharmaceutical formulations and is therefore safe to be used in microalgal/cyanobacterial biotechnology towards food or feed production.

A. platensis is a species that has been extensively studied and has been demonstrated that it is capable of growing well heterotrophically or mixotrophically on glucose [4-6]. However, there are only few works examining its cultivation using glycerol as organic source $[7,8]$. These studies $[7,8]$ conclude that $A$. platensis can utilize glycerol as organic substrate producing higher biomass concentrations than under phototrophic conditions (i.e., using bicarbonate as the sole carbon source). However, one of the main disadvantages of heterotrophic/mixotrophic cultivation is the need for sterilization of the growth medium and the conduction of the cultivation under sterile/aseptic conditions in order to avoid contamination with unwanted heterotrophs (bacteria, fungi etc.) with probably negative impacts on growth and overall cultivation performance. A. platensis is an alkaliphile that thrives at elevated $\mathrm{pH}$ values (up to 11) and salt concentrations (> $25 \mathrm{mS} / \mathrm{cm}$ ), conditions that may suppress the propagation of many bacteria [9]. However, there is lack of published works on this topic. Moreover, it has been demonstrated that assimilation of organic carbon is affected by light intensity, and more specifically under low light intensities organics are assimilated more efficiently $[10,11]$. Therefore, main aim of this study was to cultivate $A$. platensis mixotrophically using glycerol as an organic source under semi-continuous and non-axenic conditions in order to evaluate the effect of glycerol concentration and light intensity on growth and biochemical composition of A. platensis. Additionally, the study aimed to examine the interaction between $A$. platensis and any potential bacteria that might also be grown on glycerol.

\section{Materials and Methods}

\subsection{Cultivation Conditions}

The cyanobacterium Arthrospira platensis SAG 21.99 used in the study was obtained from SAG (Sammlung von Algenkulturen der Universität Göttingen). The cultivation of $A$. platensis was performed in modified Zarrouk medium with the following composition (per L): $10 \mathrm{~g} \mathrm{NaHCO}_{3}, 0.5 \mathrm{~g} \mathrm{~K}_{2} \mathrm{HPO}_{4}$, $1.0 \mathrm{~g} \mathrm{~K}_{2} \mathrm{SO}_{4}, 1.0 \mathrm{~g} \mathrm{NaCl}, 0.04 \mathrm{~g} \mathrm{CaCl}_{2}, 0.08 \mathrm{~g} \mathrm{Na}_{2}$ EDTA, $0.2 \mathrm{~g} \mathrm{MgSO}_{4} \cdot 7 \mathrm{H}_{2} \mathrm{O}, 0.01 \mathrm{~g} \mathrm{FeSO}_{4} \cdot 7 \mathrm{H}_{2} \mathrm{O}$ and $1.0 \mathrm{~mL}$ of trace elements (per l): $2.86 \mathrm{~g} \mathrm{H}_{3} \mathrm{BO}_{3}, 0.02 \mathrm{~g}\left(\mathrm{NH}_{4}\right)_{6} \mathrm{Mo}_{7} \mathrm{O}_{24}, 1.8 \mathrm{~g} \mathrm{MnCl}_{2} \cdot 4 \mathrm{H}_{2} \mathrm{O}, 0.08 \mathrm{~g} \mathrm{CuSO}_{4}$ $5 \mathrm{H}_{2} 0$ and $0.22 \mathrm{~g} \mathrm{ZnSO}_{4} \cdot 7 \mathrm{H}_{2} \mathrm{O} . \mathrm{NaHCO}_{3}$ was used in the cultivation medium in order to ensure that no carbon limitation will occur and to help evaluate whether glycerol was used as energy and not as carbon source for mixotrophic growth of A. platensis. Under carbon limited conditions the expected $\mathrm{CO}_{2}$ generated through the degradation of glycerol by the grown bacteria would lead to false results about glycerol assimilation. An inoculum of $500 \mathrm{mg} / \mathrm{L}$ was used, while the initial $\mathrm{pH}$ of the medium was adjusted to 8 [12]. The cultivations were carried out in $370 \mathrm{~mL}$ photobioreactors (PBR) of $71 \mathrm{~mm}$ diameter with a working volume of $250 \mathrm{~mL}$. Cultures were aerated with sterile air (filtrated through $0.2 \mu \mathrm{m})$, using a membrane air pump and were conducted in temperature-controlled room with 
constant temperature at $30( \pm 2)^{\circ} \mathrm{C}$. Light was provided on the one side of the PBR by two $14 \mathrm{~W}$ LED lamps (one cool white and one of plant grow color-mixture of red and blue). Cultures were conducted in semi-continuous mode and the feeding (and withdrawal) was performed once per day at a dilution rate equal to $20 \%$ of the working volume of the culture. The experimental cultures were kept for at least 3 weeks to reach semi-steady state.

\subsection{Experimental Set-Up}

The study was divided into two phases. In the first phase A. platensis was cultivated with 0.5 , 1 and $1.5 \mathrm{~g} / \mathrm{L}$ of glycerol under 5, 10 and $15 \mathrm{Klux}$ light intensity for each glycerol concentration. Light intensity was measured in the middle of the PBR and was regulated by adjusting the distance of the PBR towards the light source. In the second phase, based on the results of the first phase, which revealed that light intensity did not influence positive the growth of $A$. platensis, a further cultivation trial was performed keeping the same cultures with increased glycerol concentration of 3,6 and $9 \mathrm{~g} / \mathrm{L}$ but only under 15 Klux of light intensity. An additional experimental (under $15 \mathrm{Klux}$ ) were carried out by supplementing the cultures with ammoniacal nitrogen in order to investigate if there is any shift of metabolic process when ammoniacal nitrogen is present in the cultivation medium. Ammoniacal nitrogen $\left(\right.$ as $\left.\mathrm{NH}_{4} \mathrm{Cl}\right)$ was supplemented every day at a rate of $20 \mathrm{mg}-\mathrm{N} / \mathrm{L} / \mathrm{d}$.

\subsection{Analytical Methods}

Biomass concentration (dry weight) was monitored by measuring optical intensity (OD) at $750 \mathrm{~nm}$ [13], while at the end of the experiments, biomass dry weight was also directly estimated (filtered biomass was dried for $2 \mathrm{~h}$ in $70^{\circ} \mathrm{C}$ ). Carbohydrates were measured by a modified phenol-sulfuric acid method [14]: briefly, in $0.5 \mathrm{~mL}$ of cell suspension containing $10-50 \mathrm{mg} / \mathrm{L}$ carbohydrates, $10 \mu \mathrm{L}$ of $90 \%$ liquefied phenol was added, mixed and followed by the addition of $1.25 \mathrm{~mL}$ of $96 \%$ sulfuric acid. After $30 \mathrm{~min}$, at room temperature, OD was measured at $485 \mathrm{~nm}$. Lipids were measured by a modification of the sulfo-vanillin method [15]: briefly, $20 \mu \mathrm{L}$ of cell suspension containing $200-500 \mathrm{mg} / \mathrm{L}$ of lipids (in order to achieve these concentrations in the samples, biomass was concentrated by centrifugation) were added in $0.4 \mathrm{~mL} 96 \%$ sulfuric acid and then samples were placed in boiling water for $10 \mathrm{~min}$. Next, samples were left at room temperature for $15 \mathrm{~min}$ to cool down and followingly $1.0 \mathrm{~mL}$ of phosphoric-acid/vanillin solution was added $(0.12 \mathrm{~g}$ of vanillin was firstly dissolved in $5 \mathrm{~mL}$ of absolute ethanol, then in $15 \mathrm{~mL}$ DI water and finally $80 \mathrm{~mL}$ of $85 \%$ phosphoric acid were added). The samples were incubated at $37^{\circ} \mathrm{C}$ for $15 \mathrm{~min}$ and $\mathrm{OD}$ was measured at $530 \mathrm{~nm}$. Proteins were assayed according to Lowry, et al. [16]: briefly, samples of $1.5 \mathrm{~mL}$ were centrifuged and the pelleted biomass was resuspended in $0.5 \mathrm{~N} \mathrm{NaOH}$ and incubated in an agitated heating plate for $15 \mathrm{~min}$. A sample of $100 \mu \mathrm{L}$ of extracted proteins were then added to $100 \mu \mathrm{L}$ SDS 5\% followed by the addition of $1 \mathrm{~mL}$ of a solution of $2 \% \mathrm{Na}_{2} \mathrm{CO}_{3}$ in $0.1 \mathrm{~N} \mathrm{NaOH}$. After $15 \mathrm{~min}$ freshly diluted (1:1 with DI water) $2 \mathrm{~N}$ Folin \& Ciocalteu reagent was added and samples were left for 30 min in dark. OD was measured at $750 \mathrm{~nm}$. Phycocyanin was extracted in $0.1 \mathrm{M}$ phosphate buffer $(\mathrm{pH} 7)$ by successive cycles of freezing and thawing biomass. The extracted phycocyanin concentration was measured spectrophotometrically and calculated as Phycocyanin $(\mathrm{mg} / \mathrm{L})=\frac{\mathrm{OD}_{615}-0.474 \times \mathrm{OD}_{652}}{5.34}$ [17]. The pigment concentration was measured according to the following equations [18]:

$$
\mathrm{Chl}_{\alpha}(\mathrm{mg} / \mathrm{L})=16.82 \times \mathrm{OD}_{665}-9.28 \times \mathrm{OD}_{652}
$$

and

Total carotenoids $(\mathrm{mg} / \mathrm{L})=\frac{1000 \times \mathrm{OD}_{470}-1.91 \mathrm{Chl}_{\alpha}-95.15\left(36.92 \times \mathrm{OD}_{652}-16.54 \times \mathrm{OD}_{665}\right)}{225}$

All biomass composition analyses were performed after washing the samples for several times with deionized $\mathrm{H}_{2} \mathrm{O}$. Dry algal biomass was measured indirectly spectrophotometrically 
at $750 \mathrm{~nm}$. All spectrophotometric determinations were carried out in Cadas 50 (Dr. Lange, Germany) spectrophotometer and analyses were carried out at least in triplicates for each replicate. The data given are their averages $(n=6)$. Quantum yield was measured in dark adapted cells (for $20 \mathrm{~min}$ ) using a handheld chlorophyll fluorometer (AquaPen-C, PSI, Czech Republic). Light color was set at red-orange $(630 \mathrm{~nm})$ and the chlorophyll fluorescence was induced using actinic illumination of $1000 \mu \mathrm{mol} / \mathrm{m}^{2} / \mathrm{s}$. This light color is intended for excitation through phycobilins and therefore is suitable for measuring cyanobacterial cultures.

Since the cultures were performed under non-aseptic conditions in order to evaluate the competition between A. platensis and potential bacteria that would grow on glycerol too, the biomass of A. platensis was estimated after its centrifugal separation from the bacteria biomass via the combination of gravitational forces and cell size. It was observed that biomass of $A$. platensis after centrifugation was separated in the bottom of the tubes, whereas bacteria were visible as cream-colored body in the upper layer above A. platensis. Thus, the upper part of the pellet was carefully collected. The difference between total $\mathrm{OD}_{750 \mathrm{~nm}}$ from the whole culture broth (including bacteria) and the $\mathrm{OD}_{750 \mathrm{~nm}}$ of the upper part (associated to bacteria) gave the $\mathrm{OD}_{750 \mathrm{~nm}}$ of A. platensis biomass concentration. The various significant differences mentioned in the text were evaluated by a statistical analysis using One-Way ANOVA at $95 \%$ confidence $(p=0.05)$.

\section{Results and Discussion}

\subsection{Effect of Light and Glycerol Concentration on the Growth Performance of A. platensis}

Figure 1a illustrates the biomass concentration of $A$. platensis cultivated with different glycerol concentrations under three light intensities. The results shown are the averages of three subsequent days of cultivation (after 3 weeks of stabilization) and reflect the semi-steady state biomass concentration of A. platensis (see Section 2.3). In all cases studied, there was a decrease on biomass concentration with the increase of glycerol concentration, except of the series of the 1st phase with ammonia $(0.5,1$ and $1.5 \mathrm{~g} / \mathrm{L}$ glycerol), where biomass concentration was almost the same for all the three glycerol concentrations. The experimental series with ammonia added performed in general better compared to those where only nitrate was used. This was not surprising because it has been frequently observed that ammonia at low concentrations can boost growth given that ammoniacal-nitrogen is preferred by microalgae/cyanobacteria compared to nitrates since its uptake and assimilation consumes less energy resulting in higher productivities [19-21].

a)

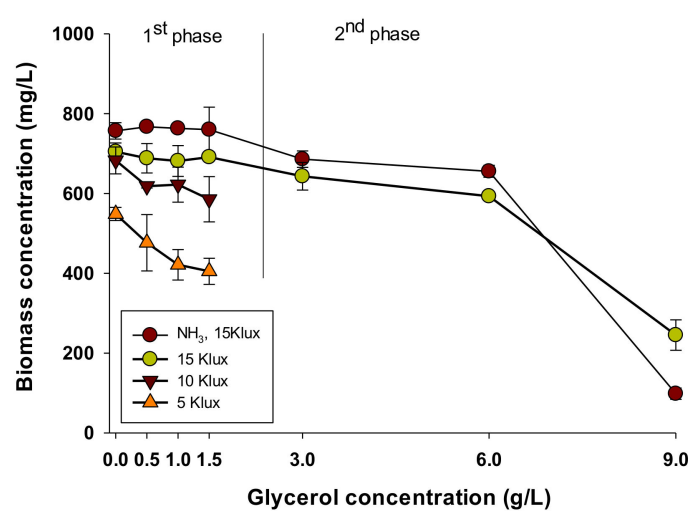

b)

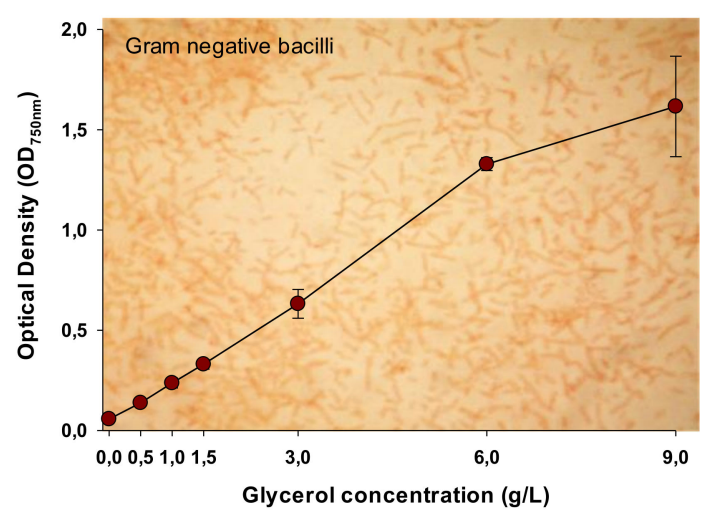

Figure 1. (a) Biomass concentration of A. platensis cultivated in semi-continuous mode in modified Zarrouk medium with the supplementation of glycerol $(0.5,1,1.5,3,6$ and $9 \mathrm{~g} / \mathrm{L})$ under three different light intensities $(5,10$ and $15 \mathrm{Klux})$ with nitrate as the nitrogen source or with ammonia as nitrogen source $\left(\mathrm{NH}_{3}\right.$ of $20 \mathrm{mg}-\mathrm{N} / \mathrm{L} / \mathrm{d}$ at $\left.15 \mathrm{Klux}\right)$. (b) Optical density $\left(\mathrm{OD}_{750 \mathrm{~nm}}\right)$ of the fraction of the bacteria grown on the A. platensis cultures with different glycerol concentrations (0.5-9 g/L). 
Since it has been demonstrated that assimilation of organic carbon is restricted as light intensity increases [10,11], it was hypothesized that under low light intensities glycerol could be assimilated more efficiently. However, as it is shown in Figure 1a there was a positive correlation between biomass concentration and light intensity, i.e., biomass concentration increased with the enhancement of light intensity from 5 to $15 \mathrm{Klux}$. It was observed that the decreasing trend of biomass concentration for each light intensity in relation to glycerol concentration was steeper at lower light intensities. The opposite trend was observed for the corresponding optical density of the bacteria present in the cultures. As it is shown in Figure $1 \mathrm{~b}$ there was an increase of the $\mathrm{OD}_{750 \mathrm{~nm}}$ related to the bacteria as glycerol concentration increased, reflecting that by increasing glycerol concentration growth of bacteria was enhanced. More specifically, the cultures were contaminated by populations of heterotrophic gram-negative bacilli (see background picture in the Figure 1b). It is though worth noting that increase of $\mathrm{OD}_{750 \mathrm{~nm}}$ of the bacteria was independent to the light intensity, showing that the most important factor for the bacterial growth was glycerol concentration. Therefore, the data shown in the Figure $1 \mathrm{~b}$ are the average of all three light intensities at the given glycerol concentration. In previous works, the bacteria isolated from the culture of A. platensis SAG 21.99 were identified as Halomonas spp., Leucobacter sp., Aeromicrobium sp., and Staphylococcus spp. [22]. The dominant bacterial species that typically contaminate A. platensis cultivation ponds, include Alkalimonas delamerensis, Cecembia lonaresis, Pseudomonas mendocina, Paenibacillus camelliae, and also members of the largely halophiles Halomonas, Mesorhizobium, Idiomarina and Micrococcus [23].

There is a subsequent question raised: Was the decreased growth capacity of A. platensis at increasing glycerol concentration due to any inhibitory effect of glycerol on A. platensis photosynthetic machinery or was it an outcome of the competition between A. platensis and the grown bacteria? In order to answer this question, chlorophyll fluorescence analysis was employed and maximum quantum yield (QY) of the Photosystem II (PSII) was recorded, which is a quantifiable indicator of the efficiency of PSII photochemistry [24]. As shown in Table 1, the QY of A. platensis did not change much $(0.48-0.56)$ between the experimental series, which suggest that $A$. platensis was not directly inhibited by the addition of glycerol, as any kind of inhibition would have been indicated by a significant decrease in the QY (values less than 0.4) [25-27]. Moreover, the $\mathrm{pH}$ of the cultures was almost the same in all experimental series ranging from 9.8-10.1, indicating that the $\mathrm{pH}$ of the growth medium was neither a cause for the biomass concentration reduction.

Table 1. Quantum Yield of A. platensis cultivated in the presence of glycerol.

\begin{tabular}{ccccc}
\hline Glycerol Concentration $\mathbf{g} / \mathbf{L}$ & $\mathbf{1 5}$ Klux & $\mathbf{1 0}$ Klux & $\mathbf{5}$ Klux & $\mathbf{N H}_{\mathbf{3}} \mathbf{- 1 5}$ Klux \\
\hline 0 & 0.52 & 0.49 & 0.50 & 0.52 \\
0.5 & 0.54 & 0.51 & 0.56 & 0.53 \\
1 & 0.54 & 0.50 & 0.56 & 0.53 \\
1.5 & 0.53 & 0.51 & 0.54 & 0.53 \\
3 & 0.49 & & & 0.50 \\
6 & 0.48 & & & 0.49 \\
9 & 0.49 & & & 0.49 \\
\hline
\end{tabular}

All the above results suggest that $A$. platensis was unable to take advantage of the addition of glycerol regarding biomass growth and moreover it was strongly competed by the bacteria grown resulting in lower cyanobacterial biomass concentrations. These results come in contrast to the results of Morais et al. [8], who reported that the addition of glycerol stimulated growth demonstrating an almost $50 \%$ increase in biomass concentration. However, the differences on the cultivation mode (batch vs. semi-continuous) the different strains used, the differences in the cultivation conditions (non-aseptic etc.) apparently have a significant effect on the results. 


\subsection{Biochemical Composition}

\subsubsection{Proteins}

As it was mentioned in the introduction, A. platensis is considered as one of the most important microalgal species that is produced in commercial level because of its nutritional value, especially for its content in proteins (up to 70\%), carbohydrates (10-20\%), phycocyanin (5-15\%), minerals and vitamins. Table 2 shows the protein content, while protein productivity of $A$. platensis grown with different glycerol concentration under the three examined light intensities is shown in Figure 2. The most apparent result is that the addition of glycerol improved the protein content of the cultures in all light intensities compared to the control (only under 5 Klux the differences were not statististical different). The increase in protein content was more intense as light intensity decreased. However, since glycerol addition had negative effect on growth, the calculation of protein productivity $(\mathrm{mg} / \mathrm{L} / \mathrm{d})$ gives a combined result on the protein content and biomass production. As it can be seen, the best results were obtained with $1,1.5$ and $0.5 \mathrm{~g} / \mathrm{L}$ of glycerol for 5 and $10 \mathrm{Klux}$, for $15 \mathrm{Klux}$ and for $\mathrm{NH}_{3}$ 15 Klux, respectively. These findings agree with the study of Morais et al. [8], where it was as well observed that glycerol addition had a positive effect on protein content.

Table 2. Protein content of $A$. platensis cultivated under different glycerol concentrations and light intensities.

\begin{tabular}{ccccc}
\hline Glycerol Concentration $\mathbf{g} / \mathbf{L}$ & $\mathbf{5}$ Klux & $\mathbf{1 0} \mathbf{~ K l u x}$ & $\mathbf{1 5} \mathbf{~ K l u x}$ & $\mathbf{N H}_{\mathbf{3}} \mathbf{- 1 5} \mathbf{~ K l u x}$ \\
\hline 0 & $39.84 \pm 5.44$ & $44.81 \pm 3.85$ & $41.96 \pm 3.52$ & $53.25 \pm 1.95$ \\
0.5 & $48.01 \pm 9.43$ & $51.65 \pm 6.26$ & $49.50 \pm 3.40$ & $59.66 \pm 2.25$ \\
1 & $58.14 \pm 6.55$ & $55.01 \pm 6.77$ & $53.20 \pm 1.60$ & $57.86 \pm 3.66$ \\
1.5 & $54.80 \pm 12.77$ & $50.58 \pm 2.96$ & $50.96 \pm 1.73$ & $56.70 \pm 4.30$ \\
3 & & & $60.70 \pm 3.62$ & $57.82 \pm 4.85$ \\
6 & & & $64.30 \pm 6.85$ & $38.36 \pm 3.88$ \\
9 & & & $15.93 \pm 2.33$ & $52.85 \pm 5.31$ \\
\hline
\end{tabular}

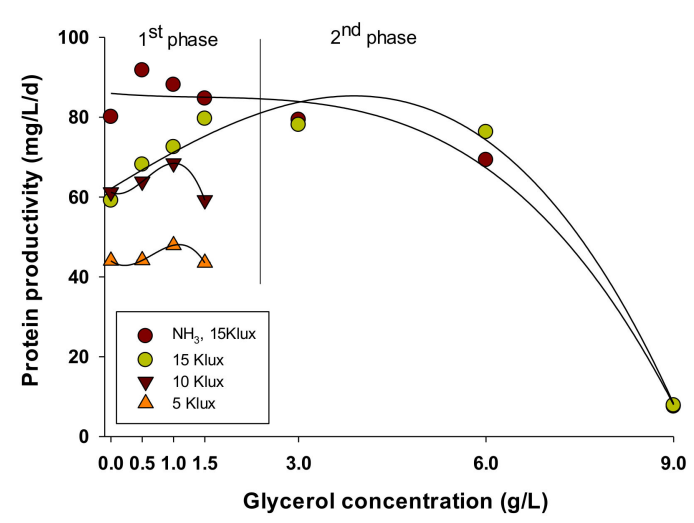

Figure 2. Protein productivity of $A$. platensis cultivated under different glycerol concentrations and light intensities.

However, given that glycerol did not result in increased growth of A. platensis it is not clear if the increase in the protein content was due to a somehow metabolic assimilation of glycerol, which resulted in the facilitation of protein synthesis and hence the increase of the protein content. Glycerol is known to be freely diffused inside cells, however till today only few species are demonstrated to utilize glycerol either as carbon or as energy source, while there is still limited knowledge about the metabolic mechanisms of its assimilation by microalgae/cyanobaceria [28-30]. On the other hand the increased protein content could be partially explained due to the presence of the bacteria, as A. platensis may activated a kind of defense mechanism to cope the competition by bacteria for resources, such as light, space and nutrients by synthesizing secondary metabolites of proteinaceous nature [31]. 


\subsubsection{Carbohydrates}

Besides proteins, carbohydrates are also major macromolecular fractions of the biomass. Carbohydrates in A. platensis are in general interesting because they can be used as feedstock for various fermentation processes for the production of chemicals and biofuels [32]. As shown in Table 3 , there was a general trend of decreasing carbohydrate content of $A$. platensis with increasing glycerol concentration. This comes in line with the results concerning protein content, showing that when protein content is decreased or increased carbohydrates are increased or decreased respectively, as an outcome of switching metabolic pathways from carbohydrates to protein synthesis and vice versa. Carbohydrates are the main products of photosynthesis and of carbon fixation metabolism. They are either stored as reserve materials or converted into components of the cell walls (polysaccharides etc.). A. platensis contain typically 10-20\% carbohydrates, which means that in the present study much higher carbohydrates content was observed. This probably is due to the semi-continuous cultivation mode performed, where cells were maintained in the exponential growth phase tending to contain more carbohydrates [33]. The decreased carbohydrate content supports the evidence that A. platensis could assimilate glycerol and utilize it for the synthesis of energy consuming compounds like proteins (see Section 3.2.1).

Table 3. Carbohydrate content of $A$. platensis cultivated under different glycerol concentrations and light intensities.

\begin{tabular}{ccccc}
\hline Glycerol Concentration $\mathbf{g} / \mathbf{L}$ & $\mathbf{5 ~ K l u x}$ & $\mathbf{1 0 ~ K l u x}$ & $\mathbf{1 5}$ Klux & $\mathbf{N H}_{\mathbf{3}} \mathbf{- 1 5}$ Klux \\
\hline 0 & $40.53 \pm 2.50$ & $35.18 \pm 1.52$ & $35.78 \pm 2.23$ & $40.48 \pm 1.82$ \\
0.5 & $32.24 \pm 2.14$ & $35.04 \pm 1.89$ & $33.17 \pm 3.01$ & $41.75 \pm 2.04$ \\
1 & $32.22 \pm 3.11$ & $32.78 \pm 2.77$ & $29.82 \pm 1.92$ & $37.98 \pm 0.84$ \\
1.5 & $32.15 \pm 1.98$ & $31.20 \pm 1.55$ & $25.48 \pm 0.99$ & $34.28 \pm 3.55$ \\
3 & & & $25.79 \pm 1.24$ & $24.20 \pm 2.61$ \\
6 & & & - & - \\
9 & & & $-19.17 \pm 2.24$ \\
\hline
\end{tabular}

\subsubsection{Lipids}

Lipids of A. platensis are of interest due to their desirable fatty acid profile comprising of relative high levels of unsaturated fatty acids, important for the nutraceutical sector [34]. In the present study A. platensis cultivated on glycerol displayed in most experimental cases a generally unchanged lipid content (Table 4), where significant higher content was obtained at the highest glycerol concentrations $(>3 \mathrm{~g} / \mathrm{L})$. These results are in line with those reported by Morais et al. [8]. Glycerol is a chemical backbone, present in many lipids which are known as glycerides. Lipid increased content could be an outcome of glycerol assimilation into the lipid biosynthesis pathway. The increase in lipid content observed only at the highest glycerol concentrations probably reflect the fact that $A$. platensis assimilates glycerol firstly in order to synthesize proteins and if glycerol is in excess then it is directed for lipid synthesis. However, the presence of bacteria does not allow us to conclude with certainty, thus more research is needed so as to confirm this hypothesis. Increasing light intensity, the lipid content of A. platensis decreased. This is in accordance with previous work [35].

\subsubsection{Pigments}

A. platensis contains two main photosynthetic pigments, namely chlorophyll- $\alpha$ and phycocyanin. Both pigments are of interest in the nutraceutical sector. Chlorophyll extract is gaining acceptance as a natural colorant or as a super-food because of its functionality, its strong antioxidant and anticancer properties [36,37]. Likewise, phycocyanin is considered as a very promising source for blue natural coloring, while it has as well functional properties [38]. In the present study, Chlorophyll- $\alpha$ content did not display a clear pattern with the increase of glycerol in the growth medium (data not shown). However, at the highest glycerol concentrations there was a significant decrease of its content 
(less than $0.5 \%$ ) compared to the control and the series where less glycerol concentrations were added $(0.8-1.05 \%)$. Phycocyanin content displayed a more or less clear trend (Table 5), i.e., it was decreased with increased glycerol concentrations. Indeed, most notable decrease was observed at the highest glycerol concentrations. The photosynthetic activity is crucial for pigment synthesis. In mixotrophic cultures, photosynthesis and heterotrophic metabolism function simultaneously. The photoautotrophic and heterotrophic metabolisms may switch to one another depending on the cultivation conditions. Therefore, the decrease in pigment (chlorophyll- $\alpha$ and phycocyanin) content was probably due to the domination of the heterotrophic over the photoautotrophic metabolism, where photosynthetic pigments are not utilized and therefore not synthesized $[4,39,40]$.

Table 4. Lipids content of $A$. platensis cultivated under different glycerol concentrations and light intensities.

\begin{tabular}{ccccc}
\hline Glycerol Concentration $\mathbf{g} / \mathbf{L}$ & $\mathbf{5 ~ K l u x}$ & $\mathbf{1 0 ~ K l u x}$ & $\mathbf{1 5} \mathbf{~ K l u x}$ & $\mathbf{N H}_{\mathbf{3}} \mathbf{- 1 5} \mathbf{~ K l u x}$ \\
\hline 0 & $7.22 \pm 0.49$ & $7.64 \pm 1.00$ & $5.89 \pm 0.58$ & $4.96 \pm 1.27$ \\
0.5 & $9.23 \pm 0.27$ & $7.32 \pm 0.20$ & $6.40 \pm 0.43$ & $5.84 \pm 0.41$ \\
1 & $8.76 \pm 0.33$ & $8.32 \pm 0.43$ & $6.36 \pm 0.26$ & $5.77 \pm 0.23$ \\
1.5 & $9.22 \pm 0.38$ & $8.44 \pm 0.85$ & $5.70 \pm 0.43$ & $5.40 \pm 0.48$ \\
3 & & & $9.46 \pm 1.05$ & $9.16 \pm 0.97$ \\
6 & & $11.13 \pm 1.45$ & $10.03 \pm 0.20$ \\
9 & & & - & - \\
\hline
\end{tabular}

Table 5. Phycocyanin content of A. platensis cultivated under different glycerol concentrations and light intensities.

\begin{tabular}{ccccc}
\hline Glycerol Concentration $\mathbf{g} / \mathbf{L}$ & $\mathbf{5 ~ K l u x}$ & $\mathbf{1 0 ~ K l u x}$ & $\mathbf{1 5}$ Klux & $\mathbf{N H}_{\mathbf{3}} \mathbf{- 1 5}$ Klux \\
\hline 0 & $12.99 \pm 0.55$ & $14.71 \pm 0.25$ & $14.20 \pm 1.38$ & $15.73 \pm 1.45$ \\
0.5 & $11.22 \pm 0.37$ & $12.86 \pm 0.1$ & $12.84 \pm 2.95$ & $14.21 \pm 2.58$ \\
1 & $12.10 \pm 0.75$ & $10.64 \pm 0.14$ & $14.83 \pm 0.25$ & $14.07 \pm 1.27$ \\
1.5 & $11.42 \pm 1.11$ & $10.55 \pm 0.46$ & $12.85 \pm 0.05$ & $12.60 \pm 0.79$ \\
3 & & & $6.60 \pm 0.25$ & $6.85 \pm 0.5$ \\
6 & & & $8.19 \pm 2.12$ & $6.13 \pm 0.34$ \\
9 & & & $1.36 \pm 1.58$ & $2.85 \pm 0.55$ \\
\hline
\end{tabular}

\section{Conclusions}

The addition of glycerol in the cultures of A. platensis had negative impact on biomass production due to the growth of bacteria that apparently outcompeted and repressed growth of A. platensis. Glycerol was not an inhibiting factor because A. platensis did not alter its photosynthetic efficiency (Quantum Yield). However, since the increase of glycerol impacted the biochemical composition (increase of protein and lipid and decrease of carbohydrate and photosynthetic pigment content) it is suggested that $A$. platensis was able to assimilate glycerol towards metabolic process for protein and lipid synthesis instead of biomass production.

Author Contributions: Conceptualization, G.M.; Methodology, G.M., E.K.; Formal analysis, G.M., E.K.; Investigation, G.M., E.K.; Resources, G.M.; Data curation, G.M.; Writing-Original draft preparation, G.M.; Writing-Review and editing, G.M., I.K., V.T., D.A., I.C.; Visualization, G.M.; Supervision, G.M.; Funding acquisition, G.M., D.A., I.C.

Funding: This research has been co-financed by the European Regional Development Fund of the European Union and Greek national funds through the Operational Program Competitiveness, Entrepreneurship and Innovation, under the call RESEARCH-CREATE-INNOVATE (T1EDK-02142).

Conflicts of Interest: The authors declare no conflict of interest. 


\section{References}

1. Borowitzka, M.A.; Vonshak, A. Scaling up microalgal cultures to commercial scale. Eur. J. Phycol. 2017, 52, 407-418. [CrossRef]

2. Chojnacka, K.; Noworyta, A. Evaluation of Spirulina sp. growth in photoautotrophic, heterotrophic and mixotrophic cultures. Enzyme Microb. Technol. 2004, 34, 461-465. [CrossRef]

3. Monteiro, M.R.; Kugelmeier, C.L.; Pinheiro, R.S.; Batalha, M.O.; da Silva César, A. Glycerol from biodiesel production: Technological paths for sustainability. Renew. Sustain. Energy Rev. 2018, 88, 109-122. [CrossRef]

4. Chen, F. High cell density culture of microalgae in heterotrophic growth. Trends Biotechnol. 1996, 14, 421-426. [CrossRef]

5. Marquez, F.J.; Sasaki, K.; Kakizono, T.; Nishio, N.; Nagai, S. Growth characteristics of Spirulina platensis in mixotrophic and heterotrophic conditions. J. Ferment. Bioeng. 1993, 76, 408-410. [CrossRef]

6. Mühling, M.; Belay, A.; Whitton, B.A. Screening Arthrospira (Spirulina) strains for heterotrophy. J. Appl. Phycol. 2005, 17, 129-135. [CrossRef]

7. Narayan, M.; Manoj, G.; Vatchravelu, K.; Bhagyalakshmi, N.; Mahadevaswamy, M. Utilization of glycerol as carbon source on the growth, pigment and lipid production in Spirulina platensis. Int. J. Food Sci. Nutr. 2005, 56, 521-528. [CrossRef]

8. Morais, E.G.; Druzian, J.I.; Nunes, I.L.; Morais, M.G.; Costa, J.A.V. Glycerol increases growth, protein production and alters the fatty acids profile of Spirulina (Arthrospira) sp LEB 18. Process Biochem. 2019, 76, 40-45. [CrossRef]

9. Shiraishi, H. Association of heterotrophic bacteria with aggregated Arthrospira platensis exopolysaccharides: Implications in the induction of axenic cultures. Biosci. Biotechnol. Biochem. 2015, 79, 331-341. [CrossRef]

10. Deng, X.; Chen, B.; Xue, C.; Li, D.; Hu, X.; Gao, K. Biomass production and biochemical profiles of a freshwater microalga Chlorella kessleri in mixotrophic culture: Effects of light intensity and photoperiodicity. Bioresour. Technol. 2019, 273, 358-367. [CrossRef]

11. Pastore, M.; Santaeufemia, S.; Bertucco, A.; Sforza, E. Light intensity affects the mixotrophic carbon exploitation in Chlorella protothecoides: Consequences on microalgae-bacteria based wastewater treatment. Water Sci. Technol. 2018, 78, 1762-1771. [CrossRef] [PubMed]

12. Markou, G.; Vandamme, D.; Muylaert, K. Ammonia inhibition on Arthrospira platensis in relation to the initial biomass density and pH. Bioresour. Technol. 2014, 166, 259-265. [CrossRef] [PubMed]

13. Griffiths, M.J.; Garcin, C.; van Hille, R.P.; Harrison, S.T.L. Interference by pigment in the estimation of microalgal biomass concentration by optical density. J. Microbiol. Methods 2011, 85, 119-123. [CrossRef] [PubMed]

14. Kochert, G. Carbohydrate determination by phenol-sulfuric acid method. In Handbook of Phycological Methods. Physiological and Biochemical Methods; Hellebust, J.A., Craige, J.S., Eds.; Cambridge University Press: London, UK, 1978; pp. 95-97.

15. Izard, J.; Limberger, R.J. Rapid screening method for quantitation of bacterial cell lipids from whole cells. J. Microbiol. Methods 2003, 55, 411-418. [CrossRef]

16. Lowry, O.H.; Rosebrough, N.J.; Farr, A.L.; Randall, R.J. Protein measurement with the Folin phenol reagent. J. Biol. Chem. 1951, 193, 265-275. [PubMed]

17. Sarada, R.; Pillai, M.G.; Ravishankar, G.A. Phycocyanin from Spirulina sp: Influence of processing of biomass on phycocyanin yield, analysis of efficacy of extraction methods and stability studies on phycocyanin. Process Biochem. 1999, 34, 795-801. [CrossRef]

18. Lichtenthaler, H.K. Chlorophylls and carotenoids: Pigments of photosynthetic biomembranes. Methods Enzymol. 1987, 148, 350-382.

19. Fernandez, E.; Galvan, A. Inorganic nitrogen assimilation in Chlamydomonas. J. Exp. Bot. 2007, 58, $2279-2287$. [CrossRef]

20. Boussiba, S.; Gibson, J. Ammonia translocation in cyanobacteria. FEMS Microbiol. Lett. 1991, 88, 1-14. [CrossRef]

21. Vílchez, C.; Vega, J.M. Nitrite uptake by Chlamydomonas reinhardtii cells immobilized in calcium alginate. Appl. Microbiol. Biotechnol. 1994, 41, 137-141. [CrossRef]

22. Choi, G.-G.; Bae, M.-S.; Ahn, C.-Y.; Oh, H.-M. Induction of axenic culture of Arthrospira (Spirulina) platensis based on antibiotic sensitivity of contaminating bacteria. Biotechnol. Lett. 2008, 30, 87-92. [CrossRef] [PubMed] 
23. Mogale, M. Identification and Quantification of Bacteria Associated with Cultivated Spirulina and Impact of Physiological Factors. Ph.D. Thesis, University of Cape Town, Cape Town, South Africa, 2016.

24. Maxwell, K.; Johnson, G.N. Chlorophyll fluorescence-A practical guide. J. Exp. Bot. 2000, 51, 659-668. [CrossRef] [PubMed]

25. Zhao, B.; Wang, J.; Gong, H.; Wen, X.; Ren, H.; Lu, C. Effects of heat stress on PSII photochemistry in a cyanobacterium Spirulina platensis. Plant Sci. 2008, 175, 556-564. [CrossRef]

26. Gong, H.; Tang, Y.; Wang, J.; Wen, X.; Zhang, L.; Lu, C. Characterization of photosystem II in salt-stressed cyanobacterial Spirulina platensis cells. Biochim. Biophys. Acta (BBA)-Bioenerg. 2008, 1777, 488-495. [CrossRef]

27. Markou, G.; Depraetere, O.; Muylaert, K. Effect of ammonia on the photosynthetic activity of Arthrospira and Chlorella: A study on chlorophyll fluorescence and electron transport. Algal Res. 2016, 16, 449-457. [CrossRef]

28. Perez-Garcia, O.; Escalante, F.M.E.; de-Bashan, L.E.; Bashan, Y. Heterotrophic cultures of microalgae: Metabolism and potential products. Water Res. 2011, 45, 11-36. [CrossRef]

29. Matson, M.M.; Atsumi, S. Photomixotrophic chemical production in cyanobacteria. Curr. Opin. Biotechnol. 2018, 50, 65-71. [CrossRef]

30. Neilson, A.; Lewin, R. The uptake and utilization of organic carbon by algae: An essay in comparative biochemistry. Phycologia 1974, 13, 227-264. [CrossRef]

31. Swamy, M.A. Chapter 6-Marine algal sources for treating bacterial diseases. In Advances in Food and Nutrition Research; Kim, S.-K., Ed.; Academic Press: Cambridge, MA, USA, 2011; Volume 64, pp. 71-84.

32. Markou, G.; Angelidaki, I.; Georgakakis, D. Microalgal carbohydrates: An overview of the factors influencing carbohydrates production, and of main bioconversion technologies for production of biofuels. Appl. Microbiol. Biotechnol. 2012, 96, 631-645. [CrossRef]

33. Wang, Y.; Chiu, S.Y.; Ho, S.H.; Liu, Z.; Hasunuma, T.; Chang, T.T.; Chang, K.F.; Chang, J.S.; Ren, N.Q.; Kondo, A. Improving carbohydrate production of Chlorella sorokiniana NIES-2168 through semi-continuous process coupled with mixotrophic cultivation. Biotechnol. J. 2016, 11, 1072-1081. [CrossRef]

34. Galasso, C.; Gentile, A.; Orefice, I.; Ianora, A.; Bruno, A.; Noonan, D.M.; Sansone, C.; Albini, A.; Brunet, C. Microalgal derivatives as potential nutraceutical and food supplements for human health: A focus on cancer prevention and interception. Nutrients 2019, 11, 1226. [CrossRef] [PubMed]

35. Tedesco, M.A.; Duerr, E.O. Light, temperature and nitrogen starvation effects on the total lipid and fatty acid content and composition ofSpirulina platensis UTEX 1928. J. Appl. Phycol. 1989, 1, 201-209. [CrossRef]

36. Humphrey, A. Chlorophyll as a color and functional ingredient. J. Food Sci. 2004, 69, C422-C425. [CrossRef]

37. Hosikian, A.; Lim, S.; Halim, R.; Danquah, M.K. Chlorophyll extraction from microalgae: A review on the process engineering aspects. Int. J. Chem. Eng. 2010, 2010, 391632. [CrossRef]

38. Romay, C.; Gonzalez, R.; Ledon, N.; Remirez, D.; Rimbau, V. C-phycocyanin: A biliprotein with antioxidant, anti-inflammatory and neuroprotective effects. Curr. Protein Pept. Sci. 2003, 4, 207-216. [CrossRef]

39. Liu, X.; Duan, S.; Li, A.; Xu, N.; Cai, Z.; Hu, Z. Effects of organic carbon sources on growth, photosynthesis, and respiration of Phaeodactylum tricornutum. J. Appl. Phycol. 2009, 21, 239-246. [CrossRef]

40. Wilken, S.; Schuurmans, J.M.; Matthijs, H.C. Do mixotrophs grow as photoheterotrophs? Photophysiological acclimation of the chrysophyte Ochromonas danica after feeding. New Phytol. 2014, 204, 882-889. [CrossRef]

(C) 2019 by the authors. Licensee MDPI, Basel, Switzerland. This article is an open access article distributed under the terms and conditions of the Creative Commons Attribution (CC BY) license (http://creativecommons.org/licenses/by/4.0/). 